\title{
Análise da qualidade das córneas doadas e do intervalo entre óbito, enucleação e preservação após a implantação de novas normas técnicas e sanitárias em Banco de Olhos Universitário
}

\author{
Comparative analysis of the donor cornea quality and of the interval between death and \\ preservation before and after new sanitary and technique rules in a University Eye Bank
}

Fabio Zantut ${ }^{1}$, Ricardo Holzchuh ${ }^{2}$, Reginaldo Carlos Boni ${ }^{3}$, Eva Cristina Mackus ${ }^{4}$, Paulo Roberto Zantut ${ }^{5}$, Claudio Nakano ${ }^{6}$, Adamo Lui Netto ${ }^{7}$, Richard Yudi Hida ${ }^{8}$

\section{RESUMO}

Objetivo: Comparar o intervalo entre o óbito e a enucleação ( $\triangle T-O-E)$, entre a enucleação e a preservação $(\triangle T-E-P)$ e a qualidade da córnea antes e após a implantação de novas normas técnicas e sanitárias baseadas na Resolução RDC 347. Métodos: Estudo retrospectivo em que foram avaliados os prontuários dos doadores de córnea do Banco de Tecidos Oculares da Santa Casa de São Paulo, 2 anos antes e 2 anos depois da implementação de novas normas sanitárias.

Resultados: Foi observado aumento do número absoluto de 205 para 374 doadores após as mudanças adotadas. Não foi observada diferença estatisticamente significante no $\Delta \mathrm{t}-\mathrm{O}$-E e $\Delta \mathrm{T}$-E-P antes e após as mudanças implantadas. Do total de 1.105 córneas doadas, foi observado 388 córneas doadas antes das mudanças e 717 córneas doadas após as mudanças implementadas. Foi observado aumento estatisticamente significante da graduação da qualidade da córnea doada de 1,76 \pm 0,90 para 1,94 \pm 0,88 após a implementação das novas normas da Resolução. Conclusão: Após as mudanças técnicas e sanitárias exigidas pela Resolução 347, houve grande aumento no número de córneas doadas, captadas e preservadas. 0 Banco de Tecidos Oculares não diminuiu os $\triangle T$ O-E e $\triangle T$ T-P. A qualidade da córnea apresentou-se inferior após as mudanças realizadas no setor.

Descritores: Transplante de córnea; Banco de olhos; Preservação de órgãos/normas; Coleta de tecidos e órgãos; Controle de qualidade

\begin{abstract}
Purpose: To compare the interval between death and enucleation ( $\triangle T-O-E)$, between enucleation and preservation $(\triangle T-E-P)$ and the quality of the cornea before and after the implantation of new technique and sanitary rules.

Methods: A retrospective study that evaluated the records of cornea donors in Sao Paulo's Santa Casa Eye Tissue Bank 2 years before and 2 years after the implementation new sanitary rules.

Results: An increase was observed in the absolute number of 205 to 374 donors following the adopted changes. There was no statistically significant difference in $\Delta t-O-E$ and $\triangle T-E-P$ before and after the implemented changes. Of the total of 1,105 donor corneas, 388 donor corneas were observed before the changes and 717 donor corneas after the implemented changes. We observed a statistically significant increase in grading of donor cornea quality from $1.76 \pm 0.90$ to $1.94 \pm 0.88$ after the implementation of new standards of resolution.

Conclusion: After the changes required by Resolution 347, there was a large increase in the number of donated, taken and preserved corneas. The BTO has not diminished the $\triangle T O-E$ and $\triangle T E-P$. Cornea quality presented itself lower after the new rules.
\end{abstract}

Keywords: Corneal transplantation; Eye banks; Organ preservation/standards; Tissue and organ harvesting; Quality control

\section{INTRODUÇÃO}

Entre os transplantes de órgãos e tecidos, o transplante mais realizado no Brasil é o de córnea, com aumento anual gradativo ${ }^{(1)}$. Isto se deve a fatores como envelhecimento da população, melhor seleção do tecido doador, novas técnicas cirúrgicas, à conscientização da população quanto à importância da doação de órgãos, atuação dos novos bancos de olhos (2), do Sistema Nacional de Transplantes (SNT), das Centrais Estaduais de Notificação, Captação e Distribuição de Órgãos (CNCDO), pelo interesse e apoio político.
O transplante de córnea tem indicações precisas com finalidades tectônicas, ópticas e terapêuticas. A avaliação do tecido é realizada pelo Banco de Tecidos Oculares (BTO), que encaminha a córnea conforme solicitada pelo cirurgião(3). O BTO tem a função de captar, avaliar e preservar córneas e escleras. Compete a essa instituição a garantia da qualidade dos tecidos captados, transportados, processados e distribuídos ${ }^{(3,4)}$.

Diversos fatores relacionados à qualidade da córnea como idade, sexo, causa mortis ${ }^{(5,6)}$, técnica de preservação, o intervalo entre o óbito
Submetido para publicação: 26 de janeiro de 2012

Aceito para publicação: 7 de outubro de 2012

Trabalho realizado no Departamento de Oftalmologia da Santa Casa de Misericórdia de São Paulo e Serviço de Captação de Órgãos e Tecidos - SCOT - da Santa Casa de Misericórdia de São Paulo - São Paulo (SP), Brasil.

Médico, Setor de Catarata, Santa Casa de Misericórdia de São Paulo, São Paulo (SP), Brasil.

Médico, Departamento de Córnea e Doenças Externas, Santa Casa de Misericórdia de São Paulo, São Paulo (SP), Brasil.

Médico, Serviço de Captação de Órgãos e Tecidos - SCOT - Santa Casa de Misericórdia de São Paulo, São Paulo (SP), Brasil.

Administradora, Serviço de Captação de Órgãos e Tecidos - SCOT - Santa Casa de Misericórdia de São Paulo, São Paulo (SP), Brasil.

Médico, Setor de Retina, Hospital das Clínicas, Faculdade de Medicina, Universidade de São Paulo - USP - São Paulo (SP), Brasil.

Médico, Setor de Retina, Santa Casa de Misericórdia de São Paulo, São Paulo (SP), Brasil.

Médico, Setor de Lentes de Contato, Santa Casa de Misericórdia de São Paulo, São Paulo (SP), Brasil.

${ }^{8}$ Médico, Banco de Tecidos Oculares, Santa Casa de Misericórdia de São Paulo, São Paulo (SP), Brasil.
Financiamento: Não houve financiamento para este trabalho.

Divulgação de potenciais conflitos de interesse: F.Zantut, Nenhum; R.Holzchuh, Nenhum; R.C.Boni, Nenhum; E.C.Mackus, Nenhum; P.R.Zantut, Nenhum; C.Nakano, Nenhum; A.Lui Netto, Nenhum R.Y.Hida, Nenhum.

Endereço para correspondência: Fabio Zantut. Rua Joaquim Candido de A. Marques, 1.517 - São Paulo (SP) - 05688-021 - Brasil - E-mail: fabiozantut@uol.com.br 
e a enucleação ( $\triangle \mathrm{t}-\mathrm{O}-\mathrm{E})$, o intervalo entre a enucleação e a preservação $(\Delta t-E-P)$, meios de preservação, tempo da córnea preservada ${ }^{(7,8)}$, entre outras variáveis, vêm sendo estudadas para garantir a boa qualidade dos tecidos e são motivos de pesquisa nos diversos bancos de olhos.

Intervalos prolongados entre $\Delta \mathrm{t}-\mathrm{O}-\mathrm{E}$ e entre $\Delta \mathrm{t}-\mathrm{E}-\mathrm{P}$ podem justificar a não liberação do tecido para transplantes ópticos ${ }^{(9,10)}$. Segundo Farias et al., a qualidade dos tecidos está inalterada em até seis horas ${ }^{(11)}$

Em 1997, a Lei 9434(4) regulamentou a remoção de órgãos, tecidos e partes do corpo humano para fins de transplante e suas normas, mas não regulamentava as instalações, normas técnicas e sanitárias dos BTOs. Isso aconteceu em dezembro de 2003 com a Resolução RDC 347 (RDC 347)

Em outubro de 2005, o Banco de Tecidos Oculares da Santa Casa de São Paulo (BTO-SCSP) teve sua estrutura modificada, baseada na RDC 347. As principais mudanças realizadas no BTO foram: melhorias no espaço físico, na preservação, que passou a ser feita em câmara de fluxo laminar, no material usado para preservação, que passou a ser específico e de uso exclusivo do BTO. Os tecidos avaliados e não avaliados passaram a ser armazenados em geladeiras separadas, com temperatura controlada e monitorada em tempo integral. Foi realizada vasta organização documental, que incluiu novo modelo de prontuários de doadores, livros de registros atualizados e elaboração do Manual Técnico Operacional com novas rotinas, procedimentos e protocolos. Passou a ser feita cobrança monetária do Sistema Único de Saúde (SUS) pela preservação e avaliação dos tecidos oculares. Tornou-se obrigatório o envio do comprovante de entrega do tecido ocular pelo cirurgião além de informações cirúrgicas do receptor. $\mathrm{O}$ quadro 1 mostra um resumo das adequações às novas normas no setor.

O objetivo deste trabalho foi comparar a qualidade da córnea doada, $\Delta \mathrm{t}-\mathrm{O}-\mathrm{E}$ e $\Delta \mathrm{t}-\mathrm{E}-\mathrm{P}$ antes e depois da implantação das novas normas técnicas e sanitárias exigidas pela Resolução RDC № 347 no BTO-SCSP.

\section{MÉTODOS}

Foram avaliados os prontuários dos doadores de córnea do BTOSCSP do período entre outubro de 2003 e outubro de 2007. Este período corresponde a 2 anos antes e 2 anos depois da implementação das novas normas técnicas e sanitárias (Outubro de 2005).

Dentre os dados disponíveis nos prontuários, foram considerados para este estudo: idade, sexo, qualidade da córnea doada, data e hora do óbito, enucleação e preservação. A graduação biomicroscópica da qualidade da córnea foi realizada à lâmpada de fenda, por um médico oftalmologista, e anotada no prontuário do doador, seguindo os critérios propostos pela Associação Panamericana de Banco de Olhos $(\mathrm{APABO})^{(12,13)}$. O examinador graduou a integridade do epitélio cor-

Quadro 1. Mudanças instituídas no Banco de Tecidos Oculares da Santa Casa de São Paulo Santa Casa de São Paulo após Resolução 347

- Preservação em câmara de fluxo laminar

- Material específico e de uso exclusivo para preservação

- Geladeira específica com temperatura monitorada 24 horas

- Elaboração do material técnico operacional com novas rotinas e protocolos

- Novo modelo de prontuário

- Livro de registros atualizados

- Envio de informações do receptor pelo cirurgião

Cobrança monetária dos procedimentos pelo SUS

- Adequação de estrutura física

Fonte: Resolução RDC 347 de 2 de dezembro de 2003. neal, a presença de halo senil, o edema estromal, as dobras de Descemet e as excrescências na Descemet (córnea guttata), seguindo a graduação: 0 (excelente), 1 (boa), 2 (razoável), 3 (ruim), 4 (péssimo). 0 examinador apresenta uma graduação final, que varia de 0 a 4, que define a finalidade terapêutica da córnea doadora. As córneas usadas para transplante óptico são as avaliadas entre 0 e 2. As com avaliação final 3 são usadas para transplante tectônico e as com avaliação 4 são descartadas. Em nosso estudo apenas a graduação final foi utilizada para comparação. Foram analisadas as variáveis: (1) número absoluto de córneas doadas, (2) $\Delta \mathrm{t}-\mathrm{O}-\mathrm{E},(3) \Delta \mathrm{t}-\mathrm{E}-\mathrm{P}$ e a (4) qualidade da córnea.

Foram excluídos deste estudo: (1) prontuários rasurados ou de difícil entendimento, (2) olhos não enucleados por qualquer razão e (3) córneas enviadas para anatomia histopatológica.

Os resultados obtidos no estudo foram expressos por médias, desvios padrões e porcentuais. Para comparar os períodos antes e depois da Resolução RDC № 347, foi utilizado o teste estatístico de Mann-Whitney para amostras não pareadas e não paramétricas. Valores de $p<0,05$ indicaram significância estatística. Os dados foram organizados em planilha Excel e analisados com o programa computacional (Instat ${ }^{\circledR}$, Graph Pad).

\section{RESULTADOS}

Foram revisados 1.346 prontuários, 184 foram excluídos por indicação de avaliação da anatomia histopatológica, 35 prontuários foram excluídos por rasura ou dificuldade de entendimento e 22 olhos não enucleados (o olho contralateral foi incluído).

Foi observado aumento do número absoluto de 205 para 374 doadores após as mudanças adotadas. A média da idade dos doadores foi de $52,85 \pm 19,78$.

No intervalo correspondente a 2 anos antes da mudança (outubro de 2003 a outubro de 2005), foi observada média de $\Delta t-O-E$ de 4,32 $\pm 3,11$ horas. No intervalo correspondente a 2 anos após a mudança (outubro de 2005 a outubro de 2007), foi observada média de $\Delta t-O$-E de 3,84 $\pm 2,54$ horas. Não foi observada diferença estatisticamente significante $(p=0,1847)$ no $\Delta t-O-E$ antes e após as mudanças implantadas (Gráfico 1).

Observamos média do $\Delta \mathrm{t}-\mathrm{E}-\mathrm{P}$ de 7,33 \pm 5,74 horas antes das mudanças implementadas e 6,01 \pm 3,38 horas após as mudanças implementadas. Não foi observada diferença estatisticamente significante $(p=0,1639)$ no $\Delta t-E-P$ antes e após as mudanças implantadas (Gráfico 2).

Do total de 1.105 córneas doadas, foi observada 388 córneas doadas antes das mudanças e 717 córneas doadas depois das mudanças implementadas. A gráfico 3 representa as distribuições da média da qualidade da córneas doadas antes e após as mudanças implementa-

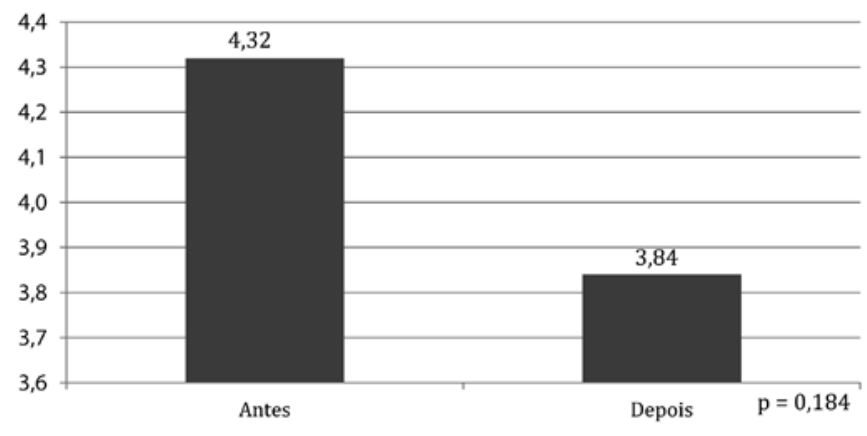

Teste estatístico de Mann-Whitney $(\mathrm{p}=0,184)$.

Gráfico 1. Comparação da média e desvio padrão do intervalo entre o óbito e a enucleação antes e após a implantação das normas exigidas da Resolução 347.

Fonte: Banco de Tecidos Oculares do Serviço de Captação de Órgãos e Tecidos (SCOT) da Santa Casa de São Paulo. 
das. Foram observadas média e desvio padrão da qualidade da córnea doada de 1,76 0,90 antes e 1,94 \pm 0,88 após a implementação das novas normas. Foi observada diferença estatisticamente significante $(p=0,0019)$.

\section{DISCUSSÃO}

Após as mudanças instituídas no BTO, observamos grande aumento do número absoluto de captação e na preservação de córneas no BTO-SCSP. Esse resultado pode ser atribuído, em parte, ao aumento do número de hospitais que passaram a fazer notificação e ao aumento de sua capacidade operacional. Com esse grande aumento dos transplantes de córnea nos últimos anos, a avaliação biomicroscópica criteriosa dos tecidos oculares tem papel de maior importância na prevenção das complicações relacionadas à má qualidade dos tecidos(6).

$\mathrm{O} \Delta \mathrm{t}-\mathrm{O}-\mathrm{E}$, que influi na qualidade da córnea segundo Van Meter et al., não foi estatisticamente diferente entre os dois grupos ${ }^{(14)}$. Saldanha et al. sugerem que o tempo menor entre essas variáveis poderia diminuir o número de córneas descartadas após preservação(15). Em nosso estudo, o $\Delta \mathrm{t}-\mathrm{O}-\mathrm{E}$ não mostrou diferença antes e após as melhorias realizadas no setor, já que a rotina dos responsáveis pela captação se manteve após as mudanças. Novas alternativas devem ser elaborados para diminuir essa variável. A captação in situ poderia ser uma alternativa ${ }^{(16)}$.

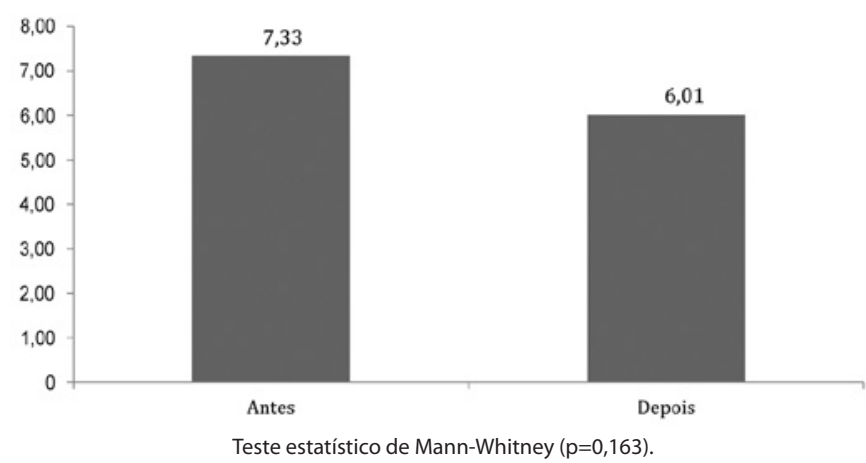

Gráfico 2. Comparação da média e desvio padrão do intervalo entre a enucleação e a preservação de córneas doadoras antes e após a implantação das normas exigidas da Resolução 347.

Fonte: Banco de Tecidos Oculares do Serviço de Captação de Órgãos e Tecidos (SCOT) da Santa Casa de São Paulo.

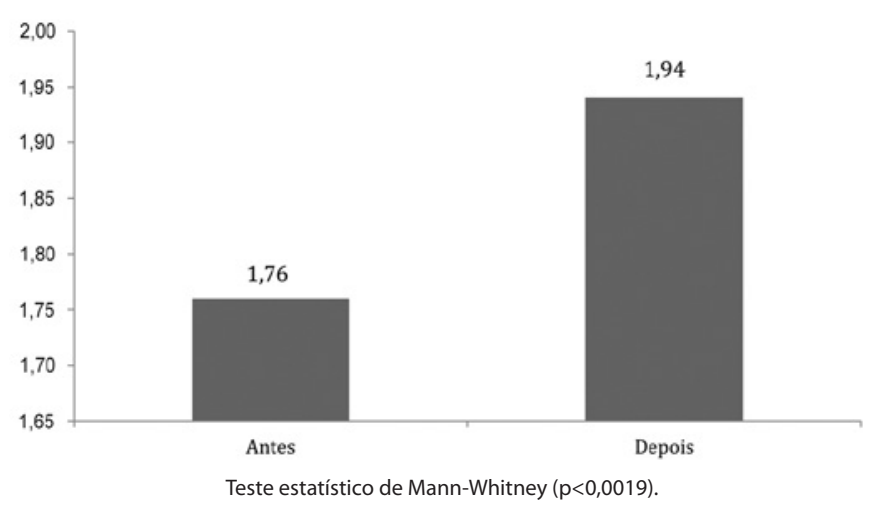

Gráfico 3. Comparação da média e desvio padrão da qualidade das córneas doadoras antes e após a implantação das normas exigidas da Resolução 347.

Fonte: Banco de Tecidos Oculares do Serviço de Captação de Órgãos e Tecidos (SCOT) da Santa Casa de São Paulo.
$\mathrm{O} \Delta \mathrm{t}-\mathrm{E}-\mathrm{P}$ que, segundo Böhringer et al. ${ }^{(7)}$, influi nos resultados dos transplantes de córnea, e Bourne ${ }^{(17)}$ que recomenda tempo menor que dez dias de preservação para atenuar a perda endotelial, não apresentou diferença estatisticamente significante ao serem comparadas $(p=0,163)$. Os residentes do Departamento incumbidos da função de preservar as córneas continuavam com a mesma função, mas após as mudanças estabelecidas nesta resolução, como nova rotina dos funcionários, presença de novos prontuários dos doadores, livro de registros atualizados, espaço físico adequado, câmara de fluxo laminar e material exclusivo, são fatores que poderiam diminuir o tempo desta variável.

Dentre as explicações para a influência do intervalo entre o óbito e a preservação e a qualidade da córnea, estão as possíveis alterações metabólicas ou até anatômicas da córnea durante esse período(5). Alguns autores observaram que o intervalo entre o óbito e a preservação pode estar associado à maior chance de defeito epitelial na córnea. Isso pode aumentar a exposição do tecido a traumatismos e à toxicidade de substâncias e medicamentos durante o período de preservação, diminuindo sua qualidade para transplante ${ }^{(10)}$. Já Slettedal et al. demonstraram a enorme capacidade regenerativa do epitélio corneal com células viáveis após sete dias do óbito ${ }^{(18)}$. Alguns autores sugerem que idade elevada e a causa do óbito podem estar associadas à perda endotelial acentuada em pacientes transplantados ${ }^{(8)}, 0$ que mostra que diversos outros fatores podem deteriorar os tecidos.

Em relação à qualidade da córnea, os resultados encontrados não foram os esperados, já que, estatisticamente, a qualidade da córnea piorou após as novas normas ( $p=0,0019)$. Uma das explicações para isso é uma possível superestimação na graduação dos parâmetros biomicroscópicos da córnea doada pelos médicos avaliadores após as mudanças implantadas. Os médicos passaram a ser mais rigorosos e o local próprio para tal procedimento permitiu melhor exame dos tecidos.

Em nossa opinião, novos critérios de avaliação da córnea doada devem ser propostos para que a subjetividade do exame seja reduzida. Melhor padronização na avaliação da córnea entre os BTOs poderia ser estabelecida para melhor comparação entre eles, para que experiências sejam trocadas e melhorias sejam propostas. A padronização poderia começar com apenas um ou no máximo dois avaliadores examinando os tecidos, para que ocorra menor diferença entre as avaliações.

Novos estudos devem ser realizados para estabelecer definitivamente a causa da piora na qualidade dos tecidos. A implantação de novas rotinas devem ser propostas para que se possam diminuir os tempos post mortem neste BTO e as próximas Resoluções devem ser criadas com esses objetivos, para que os BTOs sejam sempre aperfeiçoados, tendo excelência na qualidade dos tecidos transplantados.

\section{CONCLUSÕES}

Podemos concluir que após as mudanças técnicas e sanitárias exigidas pela Resolução 347 houve grande aumento no número de córneas doadas, captadas e preservadas.

Não foi observada diferença no intervalo entre o óbito e a preservação após as mudanças exigidas, porém foi observada piora na qualidade da córnea doada após as mudanças implementadas.

\section{REFERÊNCIAS}

1. Associação Brasileira de Transplantes de Órgãos. Registro Brasileiro de Transplantes. Transplantes. Estatísticas de transplantes. Gráficos 2007. [Internet]. 2009 [citado 2010 (Mar 04)]; Disponível em: http://www.abto.org.br/abtov02/portugues/populacao/ transplantes/estatisticasDeTransplantes.aspx?idCategoria $=5$

2. Lindquist TD, McGlothan JS, Rotkis WM, Chandler JW. Indications for penetrating keratoplasty: 1980-1988. Cornea. 1991;10(3):210-6.

3. Silva RF, Vargas NU, Rocha GA, Freitas ML, Souza LB, Moreno NP, et al. Avaliação de tecido corneano processado por um Banco de Olhos de referência. Arq Bras Oftalmol. 2009;72(5):673-6. 
4. Resolução - RDC № 347, de 02 de dezembro de 2003. Determina Normas Técnicas para o Funcionamento de Bancos de Olhos [Internet]. [citado 2012 Nov 30]. Disponível em: http://www.brasilsus.com.br/index.php?option=com_content\&view= article\&id $=12982$

5. Pantaleão GR, Zapparolli M, Guedes GB, Dimartini Junior WM, Vidal CC, Wasilewski D, et al. Avaliação da qualidade das córneas doadoras em relação à idade do doador e causa do óbito. Arq Bras Oftalmol. 2009;72(5):631-5.

6. Sano RY, Sano FT, Dantas MC, Lui AC, Sano ME, Lui Neto A. Análise das córneas do Banco de Olhos da Santa Casa de São Paulo utilizadas em transplantes. Arq Bras Oftalmol. 2010;73(3):254-8

7. Böhringer D, Reinhard T, Spelsberg H, Sundmacher R. Influencing factors on chronic endothelial cell loss characterised in a homogeneous group of patients. $\mathrm{Br} J$ Ophthalmol. 2002;86(1):35-8

8. Redbrake C, Becker J, Salla S, Stollenwerk R, Reim M. The influence of the cause of death and age on human corneal metabolism. Invest Ophthalmol Vis Sci. 1994;35(9): 3553-6. Comment in Invest Ophthalmol Vis Sci. 1995:36(2):259.

9. Adán CB, Diniz AR, Perlatto D, Hirai FE, Sato EH. Dez anos de doação de córneas no Banco de Olhos do Hospital São Paulo: perfil dos doadores de 1996 a 2005. Arq Bras Oftalmol. 2008;71(2):176-81.

10. Terry MA, Shamie N, Chen ES, Hoar KL, Phillips PM, Friend DJ. Endothelial keratoplasty: the influence of preoperative donor endothelial cell densities on dislocation, primary graft failure, and 1-year cell counts. Cornea. 2008;27(10):1131-7.

11. Farias RJ, Kubokawa KM, Schirmer M, Sousa LB. Avaliação de córneas doadoras em lâmpada de fenda e microscopia especular durante o período de armazenamento. Arq Bras Oftalmol. 2007;70(1):79-83.

12. Associação Panamericana de Banco de Olhos (APABO). [Internet]. 2010 [citado; Disponível em: http://www.apabo.com.br.

13. Batlle JF. Eye banking in Latin America. Cornea. 2002;21(6):541.

14. Van Meter WS, Katz DG, White $H$, Gayheart R. Effect of death-to-preservation time on donor corneal epithelium. Trans Am Ophthalmol Soc. 2005:103:209-22; discussion 222-4.

15. Saldanha BO, Oliveira RE Jr, Araújo PL, Pereira WA, Simão Filho C. Causes of nonuse of corneas donated in 2007 in Minas Gerais. Transplant Proc. 2009;41(3):802-3.

16. Kim JH, Kim MJ, Stoeger C, Clover J, Kim JY, Tchah H. Comparison of in situ excision and whole-globe recovery of corneal tissue in a large, single eye bank series. Am J Ophthalmol. 2010;150(3):427-33.e1.

17. Bourne WM. Endothelial cell survival on transplanted human corneas preserved at 4 C in 2.5\% chondroitin sulfate for one to 13 days. Am J Ophthalmol. 1986;102(3):382-6.

18. Slettedal JK, Lyberg T, Ramstad H, Beraki K, Nicolaissen B. Regeneration of the epithelium in organ-cultured donor corneas with extended post-mortem time. Acta Ophthalmol Scand. 2007;85(4):371-6. 